\title{
Sciatic Nerve Block in the Popliteal Fossa Using Lateral Approach in an Infant with Goldenhar Syndrome
}

\author{
Marinella Astuto*, Concetta Privitera, Carmelina Gurrieri, Giuseppe Guzzetta, Paolo Murabito, Concetta \\ Gullo, Roberta Puntillo and Antonino Gullo
}

\author{
Department of Anesthesiology and Intensive Care, Policlinico-Vittorio Emanuele University Hospital, via Santa Sofia \\ 78, 95123, Catania, Italy
}

\begin{abstract}
Goldenhar syndrome is a rare disorder characterized by a wide range of congenital malformations that may cause difficulty in tracheal intubation and mask ventilation. We describe a case of a male infant with Goldenhar syndrome successfully treated with general anesthesia with laryngeal airway mask and peripheral nerve block for club foot disease surgery.
\end{abstract}

Keywords: Difficult airway, Goldenhar syndrome, Pediatric regional anesthesia, Peripheral nerve block.

\section{INTRODUCTION}

Goldenhar syndrome was first described by Dr. Maurice Goldenhar in 1952. It affects predominately males and it usually presents with cleft palate, malar and mandibular hypoplasia, micrognathia, deafness and cervical vertebral hypoplasia [1]. Due to the airway and facial anomalies, tracheal intubation and mask ventilation may be difficult [2]. In cases with difficulty in airway management, regional anesthesia is generally used in combination with general anesthesia to reduce the anesthetic depth and the risks associated with deeper anesthetic planes, lower airway instrumentation such as laryngoscopy, as well as the need for respiratory assistance, muscle relaxants and opioids [3-5]. Regional anesthesia provides also other advantages like smoother and more comfortable emergence and faster wake-up times which represent a challenge in syndromic patients with potential difficult airway management [6]. We describe a case of Goldenhar syndrome undergoing orthopedics surgery treated with sciatic nerve block through lateral approach at our institution.

\section{CASE REPORT}

A five-months old, $5 \mathrm{~kg}$, Caucasian male with Goldenhar Syndrome was scheduled for unilateral club foot disease surgery (left side). The child had cerebral ventricular dilatation, thyroid hypofunction, kidney and urinary tract malformations. He was previously operated for hypertrophic pyloric stenosis and interventricular sept defect. There was information about difficulty in tracheal intubation but not in mask ventilation in both operations. We decided to perform sciatic nerve block through lateral approach under general anesthesia with laryngeal mask airway (LMA).

Special attention was paid to the possibility of difficulties in airway management and an emergency airway cart was

\footnotetext{
*Address correspondence to this author Policlinico-Vittorio Emanuele University, via Santa Sofia 78, 95123 Catania, Italy; Tel: 00393387915943; Fax:00390953781117; E-mail: astmar@tiscali.it
}

available in the operating room. Anesthesia was induced with sevoflurane $8 \%$ in $50 \%$ O2/Air and a size 1 LMA was used to secure the airway. Anesthesia was maintained with sevoflurane at $1 \mathrm{MAC}$ and the lungs ventilated with assisted ventilation. We then performed a sciatic nerve block in the poplitea fossa through lateral approach using a nerve stimulator (Stimuplex; B Braun, Melsungen, Germany). We identified the superior margin of the kneecap and the dome between the femoral biceps and the vastus lateralis muscles, a 22 G $(35 \mathrm{~mm}$ ) needle (Stimuplex needle B. Braun Melsungen, Germany) was inserted at $2.5 \mathrm{~cm}$ cranially the crossing point between the superior margin of the kneecap and the dome $[7,8]$. The correct needle placement was identified when an output $<0.5 \mathrm{~mA}$ elicited a characteristic plantar dorsiflexion. A total volume of $2.5 \mathrm{ml}(2.5 \mathrm{mg} / \mathrm{kg})$ of levobupivacaine $0.25 \%$ was injected. We used a nerve stimulator because ultrasound was not available at our institution $[9,10]$. Anesthesia lasted for 30 minutes during which the patient's course was uneventful. He was observed in the Post Anesthesia Care Unit for 30 minutes and transferred to the surgical ward with an Aldrete score $\geq 8$ [11,12]. Pain and motor blockade were evaluated using the CRIES scale [13] and the Bromage score [14] respectively. CRIES score was 2 at the arrival in the Post Anesthesia Care Unit, 1 at 15 and at 30 minutes after surgery. The Bromage value was 3 at the end of the procedure, 1 and 0 at 15 and 30 minutes respectively after surgery. No postoperative complications occurred. The child was discharged the day after in good and stable condition.

\section{DISCUSSION}

We report a case of Goldenhar syndrome successfully treated with a combination of general anaesthesia with LMA and peripheral nerve block for club foot disease surgery [15]. Peripheral nerve blocks are safe in children even though they are not widely used as central blocks [16] which, however, are not free from complications as reported by large studies conducted in France [17-20]. They also reduce anesthetic depth and lower airway instrumentation such as laryngo- 
scopy, as well as the need for respiratory assistance, muscle relaxants and opioids [10, 17-18]. In our case, we preferred the lateral approach to maintain the patient in the supine position, thus without compromising the safety of the airway, as previous difficult intubation has been reported [21]. This choice moreover, allowed us to use the LMA to secure the airway, offering many advantages over tracheal intubation, such as extubation and smooth emergence from anesthesia. [22] Sciatic nerve block for foot and limb surgeries in children is widely used [23,24], generally through the posterior approach. $[25,26]$ We performed the block using a nerve stimulator technique, as we have not enough experience with ultrasound. However, we agree with other experts who consider ultrasound-guided peripheral nerve blockade more efficient, less painful, and more successful than landmark and nerve stimulation techniques. [7, 27-29] We have already started to perform peripheral nerve blocks in children using nerve stimulator together with ultrasound which may increase the success rate comparing to nerve stimulator alone [30]. Ultrasound may also improve the ability of the anesthesiologists, especially those who do not perform regional anesthesia routinely, to identify the neural structures, place the block needle in close proximity to the target and precisely administer optimal volumes of local anesthetic [31,26]. However, the American Society of Regional Anesthesia Evidence-Based Medicine Assessment has found no evidence of any safety advantages for ultrasound over nerve stimulator in regard to major complications such as persistent neurological injury or systemic local anesthetic toxicity [32]. At our institution we perform peripheral blocks generally using ropivacaine $0.2 \%$ or levobupivacaine $0.25 \%$ as local anesthetics. As known, in fact, ropivacaine and levobupivacaine [Senantiomers] are less toxic than racemic bupivacaine [3336]. In this case we used levobupivacaine $0.25 \%$ at the dosage of $0.5 \mathrm{ml} / \mathrm{kg}$ [37] which provided good postoperative analgesia, reduced the need of administering other drugs such as opioids lowering the risks associated with them especially in a child with compromised airway.

\section{CONCLUSION}

Pediatric regional anesthesia is an universally applied technique in the daily clinical practice. It has a good safety profile and it can offer several advantages. In particular, in this case of Goldenhar syndrome with the possibility of difficulty in airway management, it provides more comfortable emergence and faster wake-up times reducing anesthetic depth and airway instrumentation.

\section{CONFLICT OF INTEREST}

The authors confirm that this article content has no conflicts of interest.

\section{ACKNOWLEDGEMENTS}

This research was carried out without funding.

\section{REFERENCES}

[1] Epstein CL. Genetic disorders and birth defects. In: Gregory GA, Ed. Pediatric Anesthesia. New York: Churchill Livingstone 2002; $707-45$.

[2] Sukhupragarn W, Rosenblatt WH. Airway management in a patient with Goldenhar syndrome: a case report. J Clin Anesth 2008; 20(3): 214-7.
[3] Vloka JD, Hadzic A, Kitain E. Anatomic considerations for the sciatic nerve block in the poplitea fossa through the lateral approach. Reg Anesth 1997; 84: 387-90.

[4] Zetlaoui PJ, Bouaziz H. Lateral approach to the sciatic nerve in the popliteal fossa. Anesth Analg 1998; 87: 79-82.

[5] Bernier J, Schrayer S, Piana F, et al. A new formula of age related anatomical landmarks for blockade of the sciatic nerve in the popliteal fossa in children using the posterior approach. Paediatr Anaesth 2008; 18(7): 602-5.

[6] Astuto M, Sapienza D, Di Benedetto VD, et al. Spinal anesthesia for inguinal hernia repair in an infant with Williams syndrome: Case report. Paediatr Anaesth 2007; 17(2): 193-5.

[7] Dillane D, Tsui BC. Is there still a place for the use of nerve stimulation? Paediatr Anaesth 2012; 22(1): 102-8.

[8] Giaufrè E, Dalens B, Gombert A. Epidemiology and morbidity of regional anesthesia in children: a one-year prospective survey of the French-Language Society of Pediatric Anesthesiologists. Anesth Analg 1996; 83(5): 904-12.

[9] Murat I, Costant I, Maud'huy H. Perioperative anesthetic morbidity in children: a database of 24,165 anesthetics over a 30 month period. Paediatr Anaesth 2004; 14(2): 158-66.

[10] Bosenberg A. Benefits of regional anesthesia in children. Paediatr Anaesth 2012; 22(1): 10-8.

[11] Aldrete JA, Kroulik D. A postanesthetic recovery score. Anesth Analg 1970; 49: 924-34

[12] Cox RG, Levy R, Hamilton MG, et al. Anesthesia can be safely provided for children in a high-field intraoperative magnetic resonance imaging environment. Paediatr Anaesth 2011; 21(4): 454-8.

[13] Krechel SW, Bildner J. CRIES: a new neonatal postoperative pain measurement score. Initial testing of validity and reliability. Paediatr Anaesth 1995; 5(1): 53-61.

[14] Ivani G, De Negri P, Coni A, et al. Comparison of racemic bupivacaine, ropivacaine and levobupivacaine for paediatric caudal anaesthesia: effects on postoperative analgesia and motor blockade. Reg Anesth Pain Med 2002; 27: 157-61.

[15] Disma N, Tuo P, Pellegrino S, et al. Three concentrations of levobupivacaine for ilioinguinal/iliohypogastric nerve block in ambulatory pediatric surgery. J Clin Anesth 2009; 21(6): 389-93.

[16] Ingelmo P, Ingelmo G, Astuto M, et al. Relative analgesic potencies of levobupivacaine and ropivacaine for caudal anesthesia in children Anesth Analg 2009; 108(3): 805-13.

[17] Lako SJ, Steegers MA, van Egmond J, et al. Incisional continuous fascia iliaca block provides more effective pain relief and fewer side effects than opioids after pelvic osteotomy in children. Anesth Analg 2009; 109: 1799-803.

[18] Rajamani A, Kamat V, Rajavel VP, et al. A comparison of bilateral infraorbital nerve block with intravenous fentanyl for analgesia following cleft lip repair in children. Pediatr Anaesth 2007; 17: 133-9.

[19] Astuto M, Rosano G, Rizzo G, et al. Complications in locoregional anestesia. Complicanze in anestesia loco-regionale Acta Anaesthesiol Ital 2005; 56: (4); 280-3.

[20] Ecoffey C, Lacroix F, Giaufré E, et al. Epidemiology and morbidity of regional anesthesia in children: a follow-up one-year prospective survey of the French-Language Society of Paediatric Anaesthesiologists (ADARPEF). Paediatr Anaesth 2010; 20(12): 1061-9.

[21] Abrahams MS, Aziz MF, Fu RF, et al. Ultrasound guidance compared with electrical neurostimulation for peripheral nerve block: a systematic review and meta-analysis of randomized controlled trials. Br J Anaesth 2009; 102: 408-17.

[22] Sukhupragarn W, Rosenblatt WH. Airway management in a patient with Goldenhar syndrome: a case report. J Clin Anesth 2008; 20(3): 214-7.

[23] Petroheilou K, Livanios S, Zavras N, et al. Sciatic lateral popliteal block with clonidine alone or clonidine plus $0.2 \%$ ropivacaine: effect on the intra-and postoperative analgesia for lower extremity surgery in children: a randomized prospective controlled study. BMC Anesthesiol 2012; 12: 2 .

[24] Miller BR. The biceps femoris muscle as a landmark for performing the popliteal sciatic nerve block using ultrasound guidance in pediatric patients. Paediatr Anaesth 2010; 20(10): 960-1.

[25] Bernière J, Schrayer S, Piana F. A new formula of age-related anatomical landmarks for blockade of the sciatic nerve in the popliteal fossa in children using the posterior approach. Paediatr Anaesth 2008;18(7): 602-5. 
[26] Ponde VC, Desai AP, Dhir S. Ultrasound-guided sciatic nerve block in infants and toddlers produces successful anesthesia regardless of the motor response. Paediatr Anaesth 2010; 20(7): 633-7.

[27] Kapral S, Greher M, Huber G, et al. Ultrasonographic guidance improves the success rate of interscalene brachial plexus blockade. Reg Anesth Pain Med 2008; 33: 253-8.

[28] Fredrickson MJ, Ball CM, Dalgleish AJ. A prospective randomized comparison of ultrasound guidance versus neurostimulation for interscalene catheter placement. Reg Anesth Pain Med 2009; 34: 590-4.

[29] Perlas A, Brull R, Chan VW, et al. Ultrasound guidance improves the success of sciatic nerve block at the popliteal fossa. Reg Anesth Pain Med 2008; 33: 259-65.

[30] Dufour E, Quennesson P, Van Robais AL. Combined ultrasound and neurostimulation guidance for popliteal sciatic nerve block: a prospective, randomized comparison with neurostimulation alone. Anesth Analg 2008; 106(5): 1553-8.

[31] Tsui B, Suresh S. Ultrasound imaging for regional anesthesia in infants, children, and adolescents. a review of current literature and its application in the practice of extremity and trunk blocks. Anesthesiology 2010; 112: 473-92.
[32] Neal JM, Brull R, Chan VW, et al. The ASRA evidence-based medicine assessment of ultrasound-guided regional anesthesia and pain medicine: executive summary. Reg Anesth Pain Med 2010; 35(Suppl 2): S1-S9.

[33] Scott DB, Lee A, Fagan D, et al. Acute toxicity of ropivacaine compared with that of bupivacaine. Anesth Analg 1989; 69: 563-9.

[34] Knudsen K, Beckman Suurku“ la M, Blomberg S, et al. Central nervous and cardiovascular effects of i.v. infusions of ropivacaine, bupivacaine and placebo in volunteers. Br J Anaesth 1997; 78: 507 14 .

[35] Bardsley H, Gristwood R, Baker H, et al. A comparison of the cardiovascular effects of levobupivacaine and rac-bupivacaine following intravenous administration to healthy volunteers. Br J Clin Pharmacol 1998; 46: 245-9.

[36] Stewart J, Kellett N, Castro D. The central nervous system and cardiovascular effects of levobupivacaine and ropivacaine in healthy volunteers. Anesth Analg 2003; 97: 412-6.

[37] Ivani G, Tonetti F. Postoperative analgesia in infants and children: new developments. Minerva Anestesiol 2004; 70(5): 399-403.

(C) Astuto et al.; Licensee Bentham Open.

This is an open access article licensed under the terms of the Creative Commons Attribution Non-Commercial License (http://creativecommons.org/licenses/by-nc/3.0/) which permits unrestricted, non-commercial use, distribution and reproduction in any medium, provided the work is properly cited. 